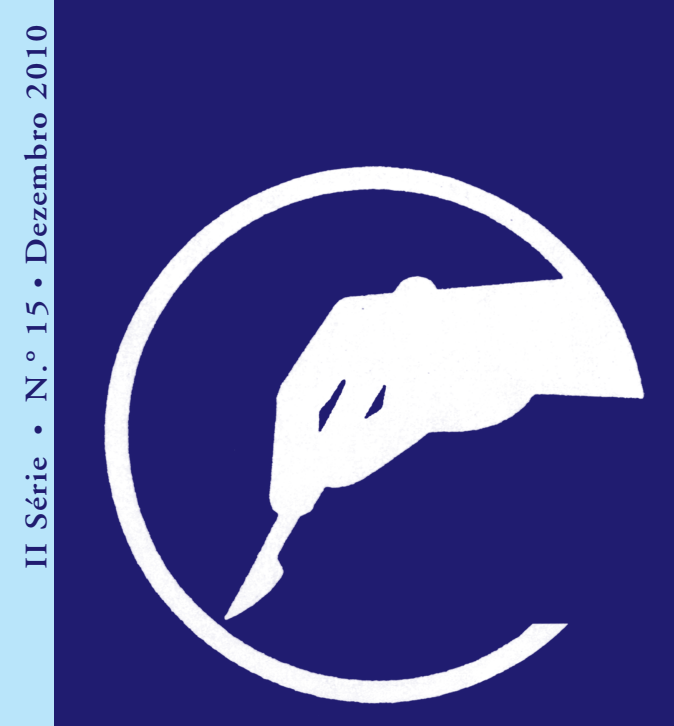

\title{
Revista Portuguesa de
}

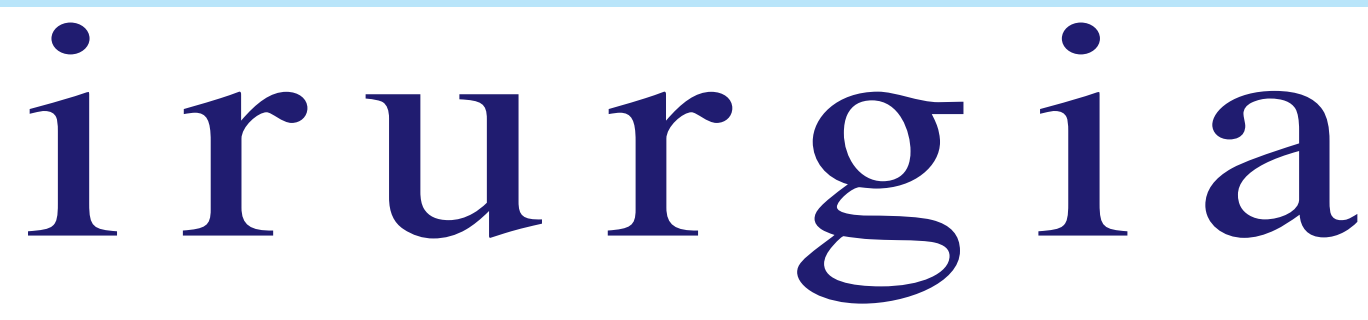

II Série • N. 15 • Dezembro 2010 


\title{
Paniculite Pancreática - caso clínico
}

\section{Pancreatic Panniculitis - case report}

\author{
Ermelindo Silva Tavares (ET) ${ }^{1}$, Joana Alexandra Devesa Parente (JAP) ${ }^{1}$, \\ Frederico Pinto Vera-Cruz (FVC) ${ }^{2}$, José Nunes Lima (JL) ${ }^{3}$, \\ João Manuel Pires Aranha (JA ${ }^{4}$, António Pedro Fernandes Estrela (APE) ${ }^{5}$
${ }^{1}$ Interno do internato complementar de Dermatologia e Venereologia - Serviço de Dermatologia e Venereologia, ${ }^{2}$ Interno do Internato Complementar de Cirurgia Geral - Serviço de Cirurgia Geral,
${ }^{3}$ Assistente Hospitalar Graduado de Cirurgia Geral - Serviço de Cirurgia Geral, ${ }^{4}$ Assistente Hospitalar de Dermatologia e Venereologia - Serviço de Dermatologia e Venereologia,
${ }^{5}$ Assistente Hospitalar de Cirurgia Geral - Serviço de Cirurgia Geral
HOSPITAL DE SANTARÉM

Autoria:

ET: b), c), 1), 4), 5), 6), 8) e 11). JAP: b), c), 1), 5) e 6). FVC: b), c), 1), 5) e 6)

JL: b), c), 1), 5) e 6). JA: b), c), 1), 5) e 6). APE: b), c), 1), 5) e 6)

Protrocínios e apoios: Sem conflitos de interesse

\section{RESUMO}

Doente do sexo feminino, de 65 anos, internada no serviço de Cirurgia Geral por quadro de pancreatite aguda, complicado de nódulos subcutâneos, eritematosos, dolorosos, localizados nas pernas, acompanhados de poliartralgias. A conjugação dos dados clínicos e analíticos com o resultado da biópsia cutânea permitiu estabelecer o diagnóstico definitivo de paniculite pancreática. A paciente beneficiou apenas de terapêutica conservadora dirigida à patologia de base. Registou-se evolução clínica favorável com desaparecimento total das lesões.

A paniculite pancreática é uma entidade clínica rara que afecta um número reduzido de doentes com distúrbio pancreático, particularmente pancreatite (aguda e crónica) e carcinoma do pâncreas. A doença caracteriza-se por necrose do tecido adiposo subcutâneo e manifesta-se, geralmente, por nódulos subcutâneos, eritematosos, dolorosos, localizados preferencialmente aos membros inferiores e, em mais de metade dos casos, verifica-se inflamação da gordura periarticular. O exame histopatológico, na maioria das vezes, revela paniculite lobular e adipócitos anucleados ("ghost cells"). O tratamento é conservador e direccionado à patologia de base.

Palavras-chave: pancreatite aguda; carcinoma pancreático; paniculite; "ghost cells".

\section{ABSTRACT}

A 65-years-old female admitted on general surgery with acute pancreatitis, complicated with painful, erythematous and subcutaneous nodules, located on the legs, followed by poliarthritis. The combination of clinical and laboratory data as well as the results of skin biopsy confirmed the diagnosis of pancreatic panniculitis. The patient was treated with conservative therapy only led to her underlying pathology. A successful outcome and disappearance of the lesions were registered.

Pancreatic panniculitis is a rare disorder that affects a small number of patients with pancreatic disorders, particularly pancreatitis (acute and chronic) and carcinoma of the pancreas. The disease is characterized by necrosis of subcutaneous adipose tissue and manifests itself usually by subcutaneous, erythematous and painful nodules, located preferentially on the lower limbs, and in more than half of the cases, there is inflammation of the periarticular fat. In the most cases, histopathology reveals lobular panniculitis and fat cells without nuclei (ghost cells). Treatment is conservative, aimed at the underlying pathology.

Keywords: acute pancreatitis, pancreatic carcinoma, panniculitis, ghost cells. 


\section{INTRODUÇÃO}

A necrose da gordura subcutânea, descrita pela primeira vez por Hans Chiari em $1883,{ }^{1}$ representa uma complicação rara nos pacientes com patologia pancreática. O seu quadro clínico é dominado por lesões cutâneas semelhantes às do eritema nodoso, e em muitos casos, envolvimento das grandes articulações; o distúrbio pancreático subjacente pode em alguns pacientes ser assintomático. Embora a pancreatite e o carcinoma pancreático constituam as principais etiologias, outras doenças pancreáticas (congénitas ou adquiridas) também foram descritas. A histopatologia é característica e permite distinguir a paniculite pancreática das outras paniculites, enquanto os achados analíticos (e os imagiológicos em certos casos) reflectem a presença de uma patologia pancreática, primária ou secundária.

Apresenta-se um caso de paniculite pancreática numa paciente com pancreatite aguda, relembrando a sua raridade e o facto de ser um sinal dermatológico que pode traduzir a gravidade de uma afecção pancreática.

\section{DESCRIÇÃO DO CASO CLÍNICO}

Doente do sexo feminino, de 65 anos, raça branca, que recorreu ao serviço de urgência (SU) do Hospital de Santarém por quadro de dor abdominal intensa, localizada ao epigastro, com irradiação para os flancos e dorso, vómitos biliosos e febre, com 2 dias de evolução. Ao exame objectivo, encontrava-se ligeiramente febril $\left(37.8^{\circ} \mathrm{C}\right)$ e a palpação abdominal profunda era dolorosa no epigastro, sem defesa, Bloomberg, massas ou organomegálias; o restante exame objectivo foi normal. Os exames complementares revelaram uma amilasémia de $2331 \mathrm{U} / \mathrm{L}$ (25-125 U/L), lipasémia de $3129 \mathrm{U} / \mathrm{L}$ (8-78 U/L), alterações discretas das provas de função hepática, leucocitose ligeira de $11 \mathrm{G} / \mathrm{L}$, com 80\% de neutrófilos (5-10 G/L) e elevação discreta da proteína $\mathrm{C}$ reactiva, estando os restantes parâmetros hematológicos e bioquímicos (hemoglobina, glicose, calcémia e L-lactato desidrogenase) dentro dos valores de referência. Realizou-se ecografia abdominal cujo resultado foi litíase vesicular, sem alterações do fígado, do baço ou do pâncreas. Os achados da radiografia do tórax e do abdominal foram irrelevantes. Perante estes resultados, estabeleceu-se o diagnóstico de pancreatite aguda litiásica edematosa, tendo a doente ficado internada no serviço de cirurgia geral com terapêutica analgésica, pausa alimentar, fluidoterapia, antibioterapia profilática, inibidor da secreção gástrica e antiemético.

No segundo dia de internamento, surgiram nódulos eritematosos, com 1-3 cm de diâmetro, dolorosos, quentes, profundos, não flutuantes, localizados nas pernas, mais intensamente a esquerda (Figura 1 e 2) e poliartralgias, aparentemente de carácter inflamatório e localizadas aos ombros, joelhos e anca esquerda. A doente apresentava na altura um bom estado geral, estava apirética, referia melhoria das queixas que motivaram o internamento e negava sintomatologia referente aos outros sistemas. O exame reumatológico revelou uma mobilização articular (activa e passiva) e

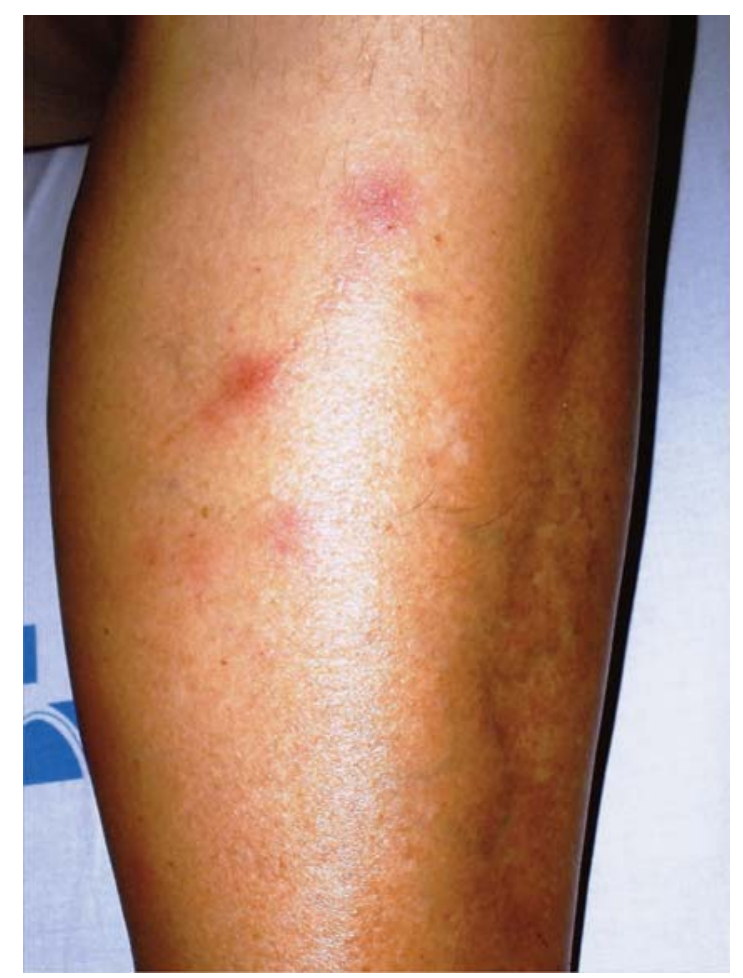

Figura 1 - Nódulos eritematosos e dolorosos localizados na perna esquerda. 


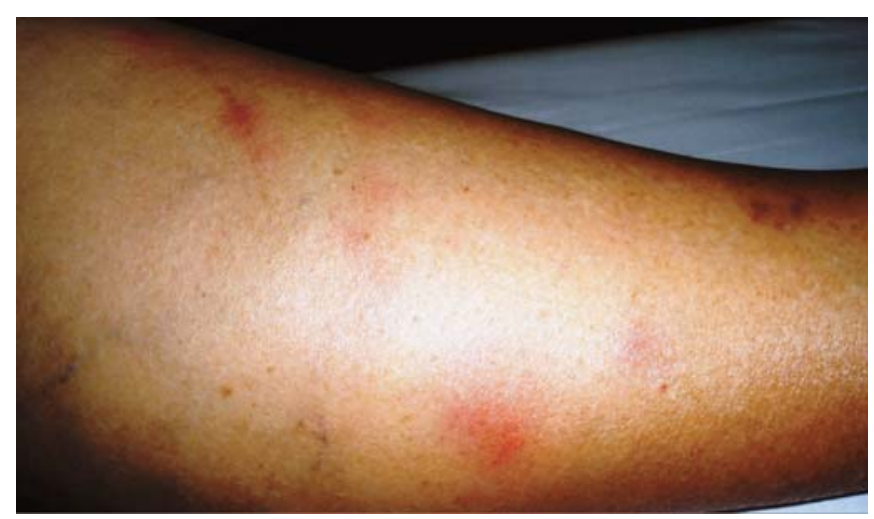

Figura 2 - Nódulos eritematosos e dolorosos localizados na perna direita

pressão da área periarticular dolorosas, com eritema discreto e sem edema.

Colocou-se como principal hipótese de diagnóstico paniculite pancreática. Realizou-se biópsia de uma das lesões cutâneas, reavaliação analítica e requisição de novos exames complementares, sendo uma delas a TAC abdominal. Nos resultados obtidos, registou-se um declínio significativo dos valores de amilase (830 U/L) e de lipase (367 U/L) e uma hipocalcémia de $1.93 \mathrm{mmol} / \mathrm{L}$ (2.2-2.6 mmol/L); o doseamento da 1antitripsina e os títulos de anticorpos antinucleares (ANA) foram normais e as serologias do VHB, VHC e HIV foram negativas, assim como o VDRL. A TAC abdominal não acrescentou novos dados ao quadro. $\mathrm{O}$ exame histológico (Figura 3) demonstrou infiltrado

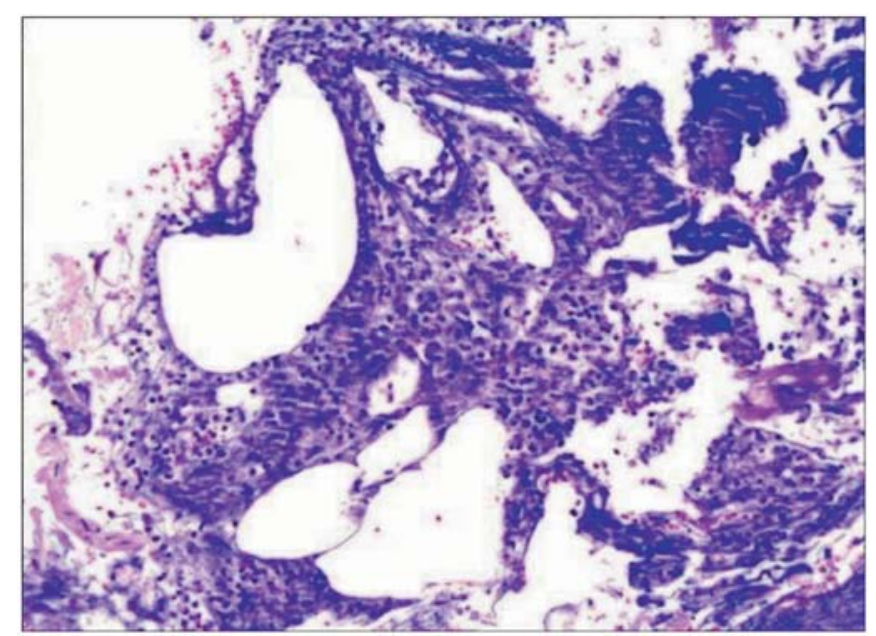

Figura 3 - Hematoxilina e eosina: Infiltrado inflamatório dérmico e subcutâneo por polimorfonucleares, depósitos de cálcio (grânulos basofílicos) e presença de células fantasmas. inflamatório denso na derme e tecido adiposo subcutâneo, constituído principalmente por polimorfonucleares, depósitos dérmicos de cálcio, paniculite lobular e adipócitos anucleados ("ghost cells"). Estabeleceuse o diagnóstico definitivo de paniculite pancreática associada a pancreatite aguda litiásica edematosa.

A doente teve alta ao décimo dia de internamento, com melhoria significativa das lesōes cutâneas, normalização das enzimas pancreáticas e da calcémia. $\mathrm{Na}$ consulta de seguimento, oito semanas após a alta, era visível apenas discreta hiperpigmentação pós-inflamatória residual.

\section{DISCUSSÃO}

A necrose do tecido adiposo pancreático e das estruturas abdominais adjacentes (omento e mesentério) é uma ocorrência comum nos pacientes com doença pancreática, especialmente a pancreatite aguda; ${ }^{2}$ contudo, o envolvimento da gordura subcutânea é um evento raro que atinge cerca de $2 \%$ dos doentes com pancreatopatia, sendo a pancreatite (aguda e crónica) e o carcinoma pancreático, especialmente o do tipo acinar, as etiologias mais comummente descritas na literatura, atingindo em algumas séries 80 a 100\% dos casos. O pseudoquisto, as neoplasias neuroendócrinas, o pâncreas divisum, a fístula arteriovenosa do Wirsung, os traumatismos, a isquémia, o lúpus eritematoso sistémico, ${ }^{3}$ a infecção pelo $\mathrm{VIH}^{3}$ e o síndrome hemofagocítico $^{3}$ estão raramente associados.

A fisiopatologia da citoesteatonecrose subcutânea permanece pouco compreendida. Segundo vários autores, as enzimas pancreáticas desempenham um papel importante no desenvolvimento das lesóes, facto que tem justificado o emprego do termo paniculite enzimática. A tripsina e a amilase promovem o aumento da permeabilidade da parede celular, facilitando a entrada da lipase no espaço intracelular, sendo a hidrólise dos triglicerídeos, a necrose e a inflamação os eventos finais. A estase venosa pode intervir como um promotor do processo, facto que possivelmente explica a predilecção das lesões pelos membros inferiores. ${ }^{1}$ 
Clinicamente, a paniculite pancreática manifestase por nódulos eritematosos, dolorosos, medindo 2 a $4 \mathrm{~cm}$, isolados ou difusos, localizados preferencialmente nos membros inferiores, podendo as lesões surgir em qualquer parte da superfície cutânea. O envolvimento articular ocorre em 55 a $80 \%$ dos casos, geralmente sob a forma de mono, oligo ou poliartrite, devido à necrose da gordura periarticular. ${ }^{2} \mathrm{~A}$ paniculite pode preceder o diagnóstico de doença pancreática em vários meses, e em caso de carcinoma, o seu aparecimento pode significar a ocorrência de metástases. Febre, dor abdominal, vómitos, eosinofilia, ${ }^{3}$ reacção leucemóide, ${ }^{3}$ hipocalcémia e derrame pleural $^{3}$ também podem estar presentes.

O diagnóstico diferencial da paniculite enzimática é feito com o eritema nodoso, o eritema induratum, o lúpus profundus, a paniculite por deficiência de 1-antitripsina, a doença de Webber-Christian, a paniculite infecciosa, a paniculite fictícia e a poliarterite nodosa. ${ }^{2,4,5}$ Os achados do exame anátomo-patológico são patognomónicos e caracterizam-se pela presença de paniculite lobular ou mista (septal e lobular), depósitos de cálcio sob a forma de material basofílico homogêneo ou granular, adipócitos desprovidos de núcleo, constituindo as típicas células fantasmas (“ghost cells") e um infiltrado inflamatório neutrofílico. No entanto, também podem ser visualizados em alguns casos eosinófilos, macrófagos e células gigantes multinucleadas. ${ }^{1}$

O tratamento da paniculite baseia-se em medidas de suporte e depende da patologia pancreática subjacente. ${ }^{5}$ Os anti-inflamatórios esteróides (tópicos ou sistémicos) e não esteróides mostraram-se ineficazes. As lesões regridem em 2 a 8 semanas, originando cicatrizes hiperpigmentadas, ${ }^{2}$ sendo esta a evolução que se registou no nosso caso clínico; na sua forma severa, as lesões torna-se flutuantes, podendo ulcerar e drenar um líquido gorduroso. A taxa de mortalidade é ditada pela gravidade da patologia de base, atingindo em algumas séries os $45 \%$ em caso de envolvimento cutâneo exclusivo e os $75 \%$ se ocorrer necrose da gordura periarticular. A associação paniculite, poliartrite e eosinofilia é conhecida por tríade de Schmid e está associada a um prognóstico reservado. ${ }^{1}$

Embora seja uma complicação rara, é imperativo excluir a presença de patologia pancreática, especialmente do foro oncológico, num paciente portador de paniculite e artrite, com ou sem queixas abdominais.

\section{REFERÊNCIAS BIBILIOGRÁFICAS}

1. Patterson WJ. Panniculitis, section 16 (100). In Bolognia JL, Jorizzo JL, Rapini RP, et al. Dermatology. Unites States: Mosby Elsevier, 2008: $1515-1535$.

2. Matte S, Melo I, Pinto M, Espadim L, Pinto C, Rubin M. Necrose da gordura subcutânea e doença pancreática: relato de caso. An bras Dermatol 1997; 72(2): 181-183. Disponível em URL: http://www. anaisdedermatologia.org.br/public/ artigo .aspx ?id=653 [acedido em 17.09.09].

3. Suwattee P. Pancreatic panniculitis in a 4-years-old child with nephrotic syndrome. Pediatric Dermatology 2007; 24 (6): 659-665.

4. Federman GD, McNiff MJ, Kirsner SR. Pancreatic Panniculitis. Wounds 2004; 16(4): 140-146. Disponível em URL: http://www.medscape.com/viewarticle/474848 [acedido em 17.09. 09].

5. Black MM, Cunliffe WJ. Fat subcutaneous, capter 55. In Burns T, Breathnach S, Cox N, Griffiths C. Rook's textbook of dermatology. England: Blackwell Publishing, 2004: 55.1-55.38.

Autor responsável:

ERMELINDO SILVA TAVARES

Serviço de Dermatologia e Venereologia

Hospital de Santarém

Avenida Bernardo Santareno

2005 - Santarém

Tlm: 963115200/910202991

tavaresmerlindo@gmail.com 